\title{
GOVERNAMENTALIDADE ALGORÍTMICA E SUBJETIVAÇÃO: SOBRE OS RISCOS DA CONSTRUÇÃO DE SUBJETIVIDADEŞ EM UM MUNDO DIGITAL
}

\author{
ALGORITHMIC GOVERNMENTALITY AND SUBJECTIVATION: ON THE RISKS OF \\ CONSTRUCTION OF SUBJECTIVITIES IN A DIGITAL WORLD
}

\author{
Rone Eleandro Santos ${ }^{1}$ \\ ${ }^{1}$ Instituto Federal do Sudeste de Minas Gerais - Campus Muriaé, Núcleo de Ciências Humanas, \\ Brasil, rone.res@live.com
}

ART I C LE INFO

Article history:

Received 2018-08-30

Accepted 2019-2-06

Available online 2019-02-07
Palavras-chave: Governamentalidade Algorítmica. Subjetivação. Mundo Digital. Antoinette Rouvroy.

Keywords: Algorithmic governmentality. Subjectivation. Digital world. Antoinette Rouvroy.

RESUMO. No presente texto busco analisar como o conceito de governamentalidade desenvolvido por Michel Foucault foi reapropriado em um novo e perspicaz modo de governo analisado pela filósofa Antoinette Rouvroy. Partindo das análises de Foucault Rouvroy busca comprovar que atualmente está em processo a instalação de um tipo completamente novo de governamentalidade que age através da otimização algorítmica dos comportamentos, das relações sociais e da própria vida dos indivíduos. O processo de "digitalização do mundo" fornece o fundamento desta "governamentalidade algorítmica" visto que os inúmeros vestígios numéricos (os dados) de nossos comportamentos, que proliferam na internet, formam um conjunto de informações tidas como mais refinadas, objetivas e que falam da realidade como ela é. Por sua objetividade a "governamentalidade algorítmica" opera através de três momentos que permitem seu funcionamento e a desviam de toda interpretação dos fenômenos, de representação do mundo e de construção de subjetividade: a dataveillance, a datamining e o profiling. Entre os "benefícios" pretendidos com a "governamentalidade algorítmica" estão a eliminação, graças aos cálculos algoritmos, de todo risco, de toda imprevisibilidade e de todo perigo. Isso aumenta a capacidade de predição dos comportamentos futuros dos indivíduos levando, no campo da segurança pública, à diminuição da ocorrência de crimes e ao amplo controle de condutas desviantes. Contrariando esta perspectiva Rouvroy ressalta que um governo alicerçado em dados digitais pode levar à constituição de uma sociedade sem vida, à eliminação de qualquer representação do mundo e, no limite, à extinção dos sujeitos e das subjetividades.

\begin{abstract}
In this paper I try to analyze how the concept of governmentality developed by Michel Foucault was reappropriated in a new and perspicacious mode of government analyzed by the philosopher Antoinette Rouvroy. Based on the analysis of Foucault Rouvroy seeks to prove that currently is in process the installation of a completely new type of governmentality that acts through the algorithmic optimization of behaviors, social relations and the prope life of individuals. The process of "digitizing the world" provides the foundation for this "algorithmic governmentality" since the numerous numerical vestiges (the data) of our behaviors, which proliferate on the internet, form a ensemble of information considered more refined, objective and that speak of reality as it is. By its objectivity the "algorithmic governamentality" operates through three moments that allow its operation and the deviation of all interpretation of the phenomena, of representation of the world and of construction of subjectivity: dataveillance, datamining and profiling. Among the "benefits" intended by "algorithmic governmentality" are the elimination, through algorithmic calculations, of all risk, of all unpredictability, and of all danger. This increases the predictive capacity of individuals' future behaviors leading, in the field of public security, to a decrease in the occurrence of crimes and to the ample control of
\end{abstract}


deviant conduct. Contrary to this perspective, Rouvroy points out that a government based on digital data can lead to the constitution of a lifeless society, to the elimination of any representation of the world and, in the limit, to the extinction of subjects and subjectivities.

\section{Introdução}

No seminário "Technologies of the self", apresentado na Universidade de Vermont (EUA) em 1982, Michel Foucault apresenta uma definição bastante sintética do que entende ser a governamentalidade 1: "Chamo 'governamentalidade' o encontro entre as técnicas de dominação exercidas sobre os outros e as técnicas de si" (FOUCAULT, 1988, 19). Nessa ocasião Foucault afirmou que cada vez mais se interessava pela interação operada entre o governo de si e o governo dos outros, pelas técnicas de dominação individual e pelo modo como um indivíduo age sobre si mesmo através das técnicas de si. É importante ressaltar que essa dominação é exercida por meio de uma relação de poder consentida - quer seja de uns sobre os outros ou de si sobre si mesmo - que requer também no consentimento e estímulo de que os sujeitos ajam sempre com liberdade. Essa definição de governamentalidade ecoa o que Foucault já havia afirmado em outra ocasião no texto " $O$ sujeito e o poder":

Quando definimos o exercício do poder como um modo de ação sobre ações dos outros, quando as caracterizamos pelo 'governo' dos homens, uns pelos outros - no sentido mais extenso da palavra, incluímos um elemento importante: a liberdade. O poder só se exerce sobre 'sujeitos livres', enquanto 'livres' - entendendo-se por isso sujeitos individuais ou

\footnotetext{
1 Traduzida do original gouvernamentalité, esta palavra inexiste tanto nos principais dicionários de língua francesa quanto no vernáculo lusitano. Em português, esta palavra é ora traduzida por governabilidade, ora por governamentalidade, o que pode resultar em confusões conceituais e de entendimento. Alfredo da Veiga-Neto, em seu artigo "Coisas de Governo...", faz a defesa do uso de governamentalidade e não governabilidade como melhor tradução para a palavra do original francês. Segundo este autor enquanto governabilidade "denota a qualidade daquele ou daquilo que se pode governar ou que se deixa governar, que é dócil, que é obediente", governamentalidade seria mais adequado ao conceito gouvernementalité cunhado por Foucault, posto que essa tradução é vista como a "qualidade segundo a qual o Estado foi se tornando governamental". Para Veiga-Neto, é preferível fazer uso do conceito governamentalidade porque este faz referência mais às questões governamentais ligadas ao surgimento do Estado Moderno do que propriamente a alguma coisa ou alguém que pode ser objeto de um processo de governo ou direção porque é dócil e obediente. Curiosamente, na tradução inglesa de gouvernamentalité, não foi utilizada a palavra governableness, já existente no dicionário, mas o conceito governmentality. Por ser um termo que facilita a compreensão das sutis diferenças existentes entre governo no sentido político e governo no sentido de condução e direção de coisas ou pessoas Veiga-Neto conclama, juntamente com governamentalidade, a "ressurreição" da palavra governamento em língua portuguesa com o intuito de "tornar mais rigoroso e mais fácil o duplo entendimento que, na perspectiva foucaultiana, é possível atribuir à palavra governo" (VEIGA-NETO, 2002, 17). De fato, a adoção e uso destes termos não carregariam mais ainda a língua portuguesa, mas contribuiria para seu enriquecimento visto sua minuciosa elaboração e significativa aplicação.
} 
coletivos que têm diante de si um campo de possibilidade onde diversas condutas, diversas reações e diversos modos de comportamento podem acontecer (FOUCAULT, 1995, 244).

Apesar de Foucault tomar com ressalva o termo "conduta", no texto anteriormente citado enfatiza ser ele o que melhor esclarece o que existe de específico nas relações de poder. A "conduta" cumpre duas funções visto que é ou "o ato de conduzir os outros (segundo mecanismos de coerção mais ou menos estritos)", ou "a maneira de se comportar num campo mais ou menos aberto de possibilidades" (FOUCAULT, 1995, 244). Exercer o poder sobre os outros é menos da ordem do cerceamento, do afrontamento entre adversários e do impedimento através de mecanismos legais e mais da ordem do governo das ações, da administração das eventualidades, da gestão dos possíveis riscos e perigos.

Este desejo de gerenciar o acaso, e tudo que diz respeito ao campo do imprevisível, aumentou progressivamente à medida em que as ações governamentais passaram, cada vez mais, a serem pautadas e decididas pelo conhecimento estatístico. O aparecimento dos computadores, a criação da internet, o crescimento exponencial do conjunto de dados digitais (concentrados no Big Data) e o uso generalizado dos algoritmos acabou por potencializar ainda mais a aspiração por antecipar os problemas e predizer comportamentos.

Fundamentada no conceito foucaultiano de governamentalidade Antoinette Rouvroy, professora na Université de Namur e pesquisadora no Centre de Recherche en Information, Droit et Société (CRIDS), tem se dedicado ao estudo da nova configuração entre saberes e poderes no universo do Big Data. Suas análises a levaram ao desenvolvimento do conceito de "governamentalidade algorítmica" que ela toma como um desdobramento da governamentalidade neoliberal trabalhada por Foucault nos cursos Segurança, Território, População (1977-1978) e Nascimento da Biopolítica (1978-1979).

\section{A GOVERNAMENTALIDADE ALGORÍTMICA EM ANTOINETTE ROUVROY}

Em seus estudos Foucault toma a governamentalidade como aquilo que designa a racionalidade própria do governo de uma população. Ela não é exercida através de formas de constrangimentos jurídico-discursivos como a lei ou através da persuasão disciplinar de normas que incidem sobre a vida social. Pelo contrário, ela compõe um tipo de poder que se exerce sobre uma população através da estruturação dos possíveis campos de ação.

A problemática da governamentalidade foi construída sobre um deslocamento e uma extensão analítica significativa. Um deslocamento analítico porque se passa da perspectiva do Estado como instituição fundante para o Estado como instituição fundada a partir das práticas e relações humanas concretas. Uma extensão analítica porque a questão do governo deve ser entendida como uma generalização das técnicas disciplinares. Enquanto 
estas últimas agem sobre a forma da exclusão (da criminalidade, da loucura, etc.), considerada como uma das faces constitutivas de parte de nossa identidade, a governamentalidade age através de práticas positivas de inclusão sobre a qual se constrói a matéria das relações sociais. Entre as técnicas disciplinares e as tecnologias do governo das condutas não existe somente o deslocamento da exclusão para a inclusão, mas também a constituição de uma nova positividade, pois o governo das condutas é tanto um problema de autogoverno quanto um problema de governo da condução dos outros. $\mathrm{Na}$ verdade, são duas questões que se encontram ligadas e formam um elo de articulação entre indivíduo e sociedade.

Em parceria com seus colegas de trabalho Thomas Berns (Université Libre de Bruxelles) e Dominique Depris (Université Catholique de Louvain) Antoinette Rouvroy realizou a retomada do conceito de governamentalidade forjado por Foucault. Suas pesquisas têm o objetivo de buscar comprovar a ideia de que atualmente está em processo a instalação de um tipo completamente novo de governamentalidade que não se fundamenta tanto na lei ou na disciplina, mas sobre a otimização algorítmica dos comportamentos, das relações sociais e da própria vida dos indivíduos. Com efeito, a especificidade da governamentalidade algorítmica, segundo Rouvroy, reside no fato de que se baseia não mais sobre normas impostas pelo Estado. Seu fundamento está nos inúmeros vestígios numéricos de nossas atitudes e comportamentos que constantemente proliferam no mundo digital da internet (muitas vezes, e em geral, sem o nosso conhecimento).

Em entrevista de 2014 Rouvroy afirmou que o conceito de governamentalidade algorítmica decorre de seu interesse pelos efeitos produzidos pela "digitalização do mundo" - onde enormes quantidades de dados oferecem novas possibilidades de modelização do social - sobre os modos de governo de conduta das condutas. Como dissemos anteriormente, segundo sua visão a governamentalidade algorítmica é fruto de um deslizamento suplementar do modo de governamentalidade neoliberal.

[Trata-se de] um modo de governo alimentado essencialmente por dados brutos (que operam como sinais infra-pessoais e a-significantes mas quantificáveis); que afetam os indivíduos sob o modo de alerta, provocando o reflexo, mais do que sob o modo da autorização, proibição ou persuasão, ao se apoiar sobre suas capacidades de entendimento e de vontade; visando essencialmente a antecipar o futuro, a limitar o possível, muito mais do que regulamentar as condutas. Os dispositivos da governamentalidade algorítmica integram o datamining: a exploração das reservas de dados massivos e brutos, que individualmente não possuem nenhum sentido, para a partir deles traçar perfis de comportamento. $O$ datamining permite gerir as pessoas de maneira personalizante, industrial, sistemática e preemptiva, se interessando por elas somente enquanto pertencentes a uma multitude de perfis (de consumidores, de delinquentes potenciais, etc) (ROUVROY, 2014, 05). 
Aqui vemos, em linhas gerais, um esboço dos principais pontos que devem ser analisados para o entendimento da governamentalidade algorítmica. O ponto de partida e a matéria-prima de todo planejamento e ação desta maneira de governar passa antes de tudo pelo imenso conjunto de dados digitais que formam o Big Data. A recente e vertiginosa proliferação dos dados numéricos tem conduzido a uma radical mudança na maneira como estatisticamente eles são tratados.

A análise estatística clássica buscou desde seu surgimento observar, classificar e analisar fenômenos coletivos ou de massa (finalidade descritiva) para, enfim, "investigar a possibilidade de fazer inferências indutivas válidas a partir dos dados observados e buscar métodos capazes de permitir esta inferência (finalidade indutiva)" (BERQUÓ, 2001, 7-8). Ela vem realizando uma categorização a priori dos dados a serem tratados. Esta categorização é sempre realizada por seres humanos a partir de suas representações do mundo. Sendo assim, estas representações são sempre distorcidas de modo a não poder reivindicar ser mais do que uma aproximação da realidade. Pensada nestes moldes a estatística não chega a resultados baseada apenas em uma pretensa objetividade dos dados e números. Nesta composição da realidade entram outros elementos que são acrescentados pelos estatísticos a partir de suas percepções, experiências e vivências que não estão presentes no conjunto de números. Ao contrário da estatística clássica a governamentalidade algorítmica opera através de três grandes momentos que permitem seu funcionamento, ao mesmo tempo em que desviam de toda interpretação dos fenômenos, representação do mundo e construção de subjetividade.

\section{1) Os três momentos da governamentalidade algorítmica}

a) Primeiro momento: coleta massiva de dados (dataveillance)

O primeiro momento é o da coleta generalizada e conservação automatizada da maior quantidade possível de dados não classificados. Esta etapa recebe o nome de dataveillance e é o momento de constituição do chamado Big Data. Os dados são coletados das mais diversas fontes e para as mais diferentes finalidades: os governos os coletam visando segurança e vigilância, controle de riscos, gestão de recursos, otimização de despesas, etc.; as empresas os recolhem visando melhoramento de marketing e publicidade, personalização de ofertas, melhoramento da gestão de estoques e de ofertas de serviços, e tudo isso mirando o crescimento no mercado e o aumento dos lucros; os pesquisadores coletam a fim de adquirir e aperfeiçoar o conhecimento científico; e mesmo indivíduos comuns colhem e compartilham com condescendência dados privados nas redes sociais, aplicativos de geolocalização, e-mails, sites de buscas, de compras, etc. Esta abundância de dados é agrupada e conservada, sob forma eletrônica, em "armazéns de dados" (datawarehouses) com ilimitada capacidade de estocagem virtual (a chamada "cloud 
storage") e acessível a qualquer computador conectado à internet. Estes dados dissociados de toda intencionalidade presente no momento em que foram produzidos serão correlacionados a outros dados também desprovidos e esvaziados de significados. Isso implica em um ocultamento de toda finalidade e de toda relação com os sujeitos que produziram estes dados.

Estes dados digitais não fazem representações da realidade e nem visam interpretála. Eles funcionam como expressão de múltiplas facetas do real, "desdobrando-o em sua totalidade, mas de maneira perfeitamente segmentada, sem fazer sentido coletivamente, senão como desdobramento do real" (ROUVROY, 2015, 39). Para Rouvroy este "comportamentalismo digital generalizado" é um fenômeno novo que não considera as particularidades dos vestígios deixados por uma compra em ambiente digital, os vestígios de geolocalização de um deslocamento ou os usos de uma palavra ou língua porque cada elemento é capturado em sua natureza mais bruta, abstraído do contexto onde surgiu e reduzido a um "dado".

Um dado não é mais que um sinal expurgado de toda significação própria e certamente é por conta disso que nós toleramos deixar esses traços, mas é também o que parece assegurar sua pretensão à mais perfeita objetividade: tão heterogêneos, tão pouco intencionados, tão materiais e tão pouco subjetivos (...). O que é interessante é o fato de que tais dados têm, como principal característica, serem perfeitamente anódinos, poderem permanecer anônimos e serem não-controláveis. (...) Esta inofensividade e esta objetividade são ambas devidas a uma espécie de evitação da subjetividade (ROUVROY, 2015, 39-40).

\section{b) Segundo momento: tratamento e mineração de dados (datamining)}

Atualmente, cada vez mais os algoritmos permitem o contínuo tratamento refinado e exaustivo de uma incomensurável quantidade de dados brutos. Dados estes espontaneamente produzidos por nossos comportamentos no universo da internet e sem nenhum condicionamento imposto por leis ou normas. Visto por este ângulo somos induzidos a pensar que este tratamento dos dados produz resultados que primam pela objetividade. Não existe interpretação dos dados porque eles falam diretamente sobre a realidade das coisas ignorando qualquer representação humana, sempre parcial, subjetiva e distorcida.

As estatísticas tradicionais são realizadas tendo em vista confirmar ou refutar hipóteses específicas sobre a realidade, e para que funcionários do governo obtenham para - Estado um conjunto de conhecimento específico e quantificado sobre os recursos humanos e materiais que tem à sua disposição; por outro lado, os objetivos do datamining são muito menos pré-orientados para qualquer fim específico (ROUVROY, 2013, 162). Aliás, utilizar termos como "objetivo" e "propósito" para se referir aos dados depositados nos 
datawarehouses pode parecer contra intuitivo. Isso porque, por definição, os "depósitos de dados" contêm uma imensa quantidade de dados recolhidos em contextos heterogêneos, para uma variedade de propósitos iniciais, que se tornam irrelevantes na fase de armazenamento nos datawarehouses. O mais próximo de um propósito é obtido durante o processo de datamining quando é realizado um "tratamento automatizado" dos dados estabelecendo "correlações sutis entre eles" (ROUVROY, 2015, 40).

O que nos parece fundamental notar aqui é o fato de que nós nos encontramos, assim, diante de uma produção de saber (saberes estatísticos constituídos de simples correlações) a partir de informações nãoclassificadas e, portanto, perfeitamente heterogêneas, a produção de saber estando automatizada, isto é, solicitando apenas um mínimo de intervenção humana e, sobretudo, dispensando toda forma de hipótese prévia (como era o caso com a estatística tradicional que 'verificava' uma hipótese), isto é, evitando novamente toda forma de subjetividade (ROUVROY, 2015, 40).

\section{c) Terceiro momento: ação sobre os comportamentos via criação de perfis (profiling)}

A correlação estatisticamente significativa entre formas de vida e modelos impessoais preditivos produz a criação de perfis (profiling) - provenientes da análise algorítmica dos dados para governar nossas condutas -, o que é aceito como sendo mais racional, menos parcial e ideologicamente incontestável. A governamentalidade algorítmica seria um procedimento objetivo e livremente consentido visto que não resulta senão dos vestígios de nossa própria atuação na internet - e de muitos outros usuários -, que constantemente proliferam e são refinados com base na conexão comum entre comportamentos aparentemente díspares.

O entendimento da criação algorítmica de perfis é melhor percebido diferenciando a "informação ao nível individual” (que é amiúde observável e perceptível ao indivíduo de onde emana) do "saber produzido no nível da elaboração de perfis" (que não está disponível nem é perceptível para os indivíduos, mas é a eles aplicado a fim de obter deles "um saber ou previsões probabilísticas" adicionais acerca de suas preferências, intenções e disposições não manifestas. Esse é o momento em que a governamentalidade algorítmica age usando estes conhecimentos probabilísticos e estatísticos para antecipar comportamentos individuais, que são conectados a perfis estabelecidos das correlações de dados garimpados do datawarehouses.

Este momento de aplicação da norma aos comportamentos individuais, cujos exemplos os mais evidentes são perceptíveis nas esferas as mais diversas da existência humana (...) nos preocupa menos aqui, senão para notar, em primeiro lugar, que a eficácia preditiva será tanto maior quanto for fruto da agregação de dados massivos, isto é, de dados que estão 'simplesmente' à altura da diversidade do próprio real; e em segundo lugar, que essa ação por antecipação sobre os comportamentos individuais poderia, no futuro, sempre se limitar mais a uma intervenção sobre seu ambiente, forçosamente, uma vez que o ambiente é ele mesmo reativo e inteligente, isto é, ele próprio recolhe dados em tempo real pela multiplicação de captores, transmite-os e os trabalha para se adaptar sem 
cessar a necessidades e perigos específicos, o que já é, no mínimo, o caso daquela parte importante da vida humana durante a qual os indivíduos estão conectados. (...) Em terceiro lugar, o perfil 'ligado' ao comportamento de um indivíduo poderia ser-lhe adaptado de maneira perfeitamente eficaz pela multiplicação das correlações empregadas, a ponto de parecer evitar o uso de toda categoria discriminante e de poder mesmo levar em conta o que há de mais particular em cada indivíduo, ainda mais afastado dos grandes números e médias (ROUVROY, 2015, 41).

Nesse horizonte desenha-se a possibilidade de uma normatividade "perfeitamente democrática" e desprovida de classificações e categorizações sociais, políticas, religiosas, étnicas, de gênero, etc. Isso porque, segundo seus defensores, os algoritmos não consideram as categorias e classes existentes socialmente, o que demonstra completa isenção e objetividade ao contrário de qualquer tipo de julgamento humano. $\mathrm{O}$ datamining e o profiling parecem não ter uma relação seletiva com o mundo real e consideram relevantes as particularidades de cada elemento da realidade, mesmo as mais insignificantes. "Não se trata mais de excluir o que sai da média, mas de evitar o imprevisível, de tal modo que cada um seja verdadeiramente si mesmo" (ROUVROY, 2015, 41).

\section{OS "BENEFÍCIOS” DA GOVERNAMENTALIDADE ALGORÍTMICA}

Os defensores de um sistema de governo baseado em decisões e ações tomadas a partir de análises algorítmicas enfatizam a completa objetividade e liberdade que lhe é inerente. Por que se pensa tão facilmente que esta nova governamentalidade é objetiva e livre? É possível apontar pelo menos duas razões. Em primeiro lugar porque a governamentalidade algorítmica é concebida como muito mais "flexível". Isso quer dizer que ela não funciona fundamentada em normas e categorias a priori pensadas por outros (o sistema legal, o Estado, etc), e que exigem de nós um constante enquadramento em proveito de perfis que se adaptam quase imediatamente a tudo que ocorre em um mundo digitalizado. Contudo, ela não nos "obriga" diretamente a uma violenta adaptação. Ela nos adapta e adequa a nossos ambientes físicos e informativos de modo que alguns comportamentos seguramente ocorrem enquanto outros não. Antes e acima de tudo ela nos afeta como uma espécie de "modo de alerta", que produzem respostas-reflexos, do que como modo de interdição e obrigação.

Em segundo lugar porque a governamentalidade algorítmica corresponde a aquilo que as sociedades capitalistas e o sistema econômico neoliberal mais deseja e busca, ou seja, a eliminação, graças aos cálculos algoritmos, de todos os riscos, toda alteração e toda imprevisibilidade. O que é particularmente atraente na governamentalidade algorítmica para o sistema neoliberal é que ela é deliberadamente voltada para o futuro, que funciona visando estabelecer uma predição que se requer segura e certeira do que vamos fazer ou 
desejar fazer. Na área da segurança, por exemplo, verifica-se um crescimento exponencial de ações políticas que, fazendo uso de cálculos estatísticos e avaliações algorítmicas, visam minorar ou mesmo eliminar toda contingência ao governar o mundo real. Nesse contexto, a predição e a prevenção do perigo substituem a identificação e remediação de suas causas.

\begin{abstract}
Basta observar os temas centrais das campanhas eleitorais no mundo Ocidental desde o 11 de setembro de 2001 para notar que a onipresente figura da incerteza tornou-se tão central que fornece segurança através da antecipação do perigo eclipsando as concorrentes prioridades políticas no nível governamental. (...) Em uma política onde as figuras onipresentes da contingência e do risco vieram ocupar o espaço central formalmente (idealmente) ocupado pela figura do bem comum, onde a prevenção da insegurança, em vez da busca de qualquer bem comum coletivamente identificado, tornou-se o papel mais importante dos governos, onde os indivíduos são socializados através do medo, um fantasma dominante é que a computação automática, ao permitir as operações complexas de datamining e um preciso e dinâmico profiling, tornarão o mundo e seus habitantes previsíveis. Isso fornece o suporte ideológico para o apoio entusiasmado de qualquer tecnologia que prometa ajudar a domar o caos. A ameaça onipresente do perigo virtual atua como um incentivo poderoso para erradicar o que quer que, no ser humano, permaneça de incerto, virtual, potencial (ROUVROY, 2011, 126-127).
\end{abstract}

\title{
4. PROGNÓSTICOS DE ELIMINAÇÃO DA VIDA, DO MUNDO E DO SUJEITO
}

Este cenário, que cada vez mais tem tomado forma através da implantação da governamentalidade algorítmica, se apresenta sempre como detentor de elementos positivos. Afinal, quem não deseja conquistar segurança e certeza? Quem não almeja eliminar preocupações, riscos e imprevistos? Para Rouvroy essa capacidade de previsibilidade e predição pode conduzir ao que considera de mais problemático que é a implantação de uma sociedade onde são extintas a vida, o mundo e o sujeito.

Uma sociedade sem vida seria o resultado extremo da tendência evocada anteriormente de erradicação da incerteza, de eliminação de todo risco. Isso não apenas para organizar a coletividade (como o fazem os programas de segurança, as empresas de seguro,...), mas também para suprimir todo imprevisto ou emergências inerentes à própria vida. Rouvroy afirma que a ideologia técnica do Big Data poderia

(...) parecer perfeitamente adaptada à inversão detectada por Georges Canguilhem da perspectiva tradicional referente ao registro das normas da vida: a vida não é submissa às normas que lhes seriam externas; é a vida, ou antes são os movimentos da vida (tornados, no que diz respeito aos movimentos da vida, eminentemente "rastreáveis" e calculáveis graças aos "feromônios digitais" emitidos de um modo quase necessário em uma vida cotidiana cada vez mais "digitalizada"), que produzem as "normas", de uma maneira absolutamente imanente (ROUVROY, 2016, 07).

Entretanto, esta "imprevisível e essencial normatividade da vida" considera o fato de que a totalidade da vida não pode ser reduzida ao material dado. A vida é sempre uma 
possibilidade, no sentido de uma potência, ou seja, uma realidade incompleta, aberta a desvios e readequações, que enfrenta sempre a possibilidade de todo tipo de risco (como a doença ou o sempre presente risco da morte). A governamentalidade algorítmica em seu anseio de otimizar os eventos e acontecimentos da vida "fecham" o digital sobre ele mesmo, o imunizando de toda possibilidade de alteração comum ao que é vivo. A ambição totalizante da ideologia do Big Data pressupõe ignorar, desativar ou neutralizar tudo o que não é passível de ser digitalizado, o que é imprevisível e indecidível. Nesse sentido, somente é aceito e considerado aquilo que pode ser disposto em um ininterrupto fluxo numérico que é heterocrônico e não sincrônico com o tempo real (ROUVROY, 2016, 07).

A extinção do mundo é tida como o corolário, também extremo, da crença atual de que poderíamos ultrapassar as representações e intermediações para acessar diretamente a realidade das coisas - e isso sem a necessidade de qualquer norma social concebida para governar nossas condutas. A governamentalidade algorítmica se encarrega de tudo isso, mas a "realidade das coisas" supostamente atingida pelos algoritmos "não constrói o mundo". A construção do mundo somente se efetua por intermédio de nossas representações mutuamente compartilhadas com os outros seres viventes. Em uma sociedade onde a governamentalidade algorítmica efetivasse sua completa implantação com decisões tomadas a partir de dados, o mundo, enquanto resultado de nossas representações comuns, perderia toda significação e não teria mais razão de ser.

Decidir em função dos dados é pretender decidir objetivamente, em função dos fatos cuja contingência se esquece. Isso equivaleria a nunca governar em função da justiça que demanda que se leve em consideração as condições dos fatos e, quando as condições são injustas, que elas sejam trocadas. Mas os dados do Big Data, porque são em sua maioria anonimizados, desindexados e descontextualizados, são absolutamente amnésicos das condições de sua produção e 'produzem' uma realidade amputada de sua contingência. Se, por exemplo, nos fatos, a maior parte dos empregos mais remunerados são ocupados por homens, os algoritmos de recomendação alimentados por estes dados - utilizados com a finalidade de objetivação das decisões de contratação ou de promoção -, repercutirão 'passivamente' enquanto 'dados objetivos' senão o resultado de preconceitos desfavoráveis às mulheres, e produzirão 'perfis de desempenho' favoráveis aos homens em detrimento de candidatas femininas. A chamada otimização das decisões pelo recurso à suposta inteligência dos dados é o oposto de uma 'mudança do mundo'. A ignorância das causas dos fenômenos em proveito da indução puramente estatística fundada sobre a detecção de correlações é um tecnoconservadorismo que tornam invisíveis e incontestáveis os preconceitos e as parcialidades que atravessam nossa 'realidade social'. Os algoritmos não governam - eles são programados mas não têm nenhum programa político, não apresentam nenhum projeto, não fazem escolhas -, eles otimizam o estado de fato (qualquer que seja a aceitação, a equidade deste estado de fato) passivamente transcrito na forma de dados digitais amnésicos das condições de sua produção. Portanto, os algoritmos não mudam o mundo. Pelo contrário, pode-se dizer que quando eles dispensam nosso interesse pelas causas dos fenômenos em favor de uma lógica puramente estatística, indutiva, não fazem mais do que reproduzir e 
amplificar as normatividades sociais dominantes sob pretexto de 'racionalizar' ou de objetivar as decisões (ROUVROY, 2016, 04).

Diante de tudo que foi dito anteriormente pode-se concluir que em uma sociedade sem vida e sem mundo, os indivíduos terão uma vida difícil enquanto "sujeitos". Aliás, é possível no limite pensar na extinção do sujeito e das subjetividades. Para esclarecer melhor é preciso explicar que os algoritmos associados ao Big Data constroem perfis genéricos, para além de qualquer indivíduo específico. Assim, eles eliminam as singularidades específicas de cada elemento constitutivo da vida que fazem e possibilitam que todo usuário do mundo digital se construa como um sujeito. Isso permite que os operadores dos algoritmos superem com relativa facilidade todas as restrições ligadas à proteção da vida privada. Desse modo, o desafio maior atualmente muito mais do que a conquista da proteção dos dados pessoais é vencer a disputa da concretização do completo desaparecimento do sujeito.

Para tentar descrever como a governamentalidade algorítmica realiza 0 desaparecimento do sujeito é possível elencar algumas maneiras como isso ocorre. Em primeiro lugar, a governamentalidade algorítmica gera o colapso de nossos desejos ao antecipar sistematicamente nossos comportamentos vindouros com base nos nossos comportamentos passados e alertando-nos sobre o que poderíamos querer fazer no futuro. As plataformas de comércio on-line, por exemplo, implantam uma espécie de curto-circuito no modo como construímos e revemos nossas escolhas de consumo objetivando se conectar diretamente aos nossos impulsos pré-conscientes. Desse modo, se ambiciona construir a passagem direta para o ato de compra minimizando ou mesmo contornando a capacidade de reflexão prévia. Em segundo lugar, a governamentalidade algorítmica não apenas realiza o colapso de nossos desejos: ela também torna mais difícil a racionalização a posteriori de nossas escolhas. Com efeito, a opacidade das recomendações algorítmicas que nos induzem a comprar não nos ajuda nem a fazer escolhas mais esclarecidas, nem a melhor identificar ou perceber, posteriormente, as razões de nossas escolhas. Ora, é precisamente nesta capacidade de reflexão que reside uma das coisas que mais caracteriza a capacidade de livre deliberação humana. Em terceiro lugar, a investigação das causas, das motivações psicológicas e o esclarecimento das trajetórias biográficas não são mais necessários. Aliás, tudo isso é, de acordo com a governamentalidade algorítmica, até potencialmente condenável aos olhos da proteção da vida privada. Dentro da lógica puramente estatística e indutiva apenas são contabilizados e levados em consideração os dados brutos e nossos vestígios descontextualizados e despersonalizados deixados após nossas incursões no ambiente digital. Os dados falam por si mesmos e não estão, supostamente, representando nada porque tudo já se encontra presente neles (de modo extremado até mesmo o próprio futuro já se encontra em estado latente nos dados). Por fim 
e em quarto lugar, como resultado da ausência de representações da realidade a governamentalidade algorítmica insere a incapacidade de formular uma crítica ao seu modo de funcionamento e a seus resultados. Com efeito, se a Governamentalidade Algorítmica for realmente objetiva a ponto de, mais do que espelhar, manifestar a própria realidade como é possível empreender uma crítica sobre ela? Ocorre mesmo um processo de impedimento ou de extirpação de toda crítica, de toda oposição, de toda recalcitrância, de toda desobediência. Assim, mais do que a docilização das consciências vemos ser implantado um "estado de impotência e inoperosidade dos sujeitos".?

Por possuir um caráter preventivo a governamentalidade algorítmica frequentemente opera em uma fase pré-consciente enquadrando as condutas e realizando uma avaliação automática e antecipativa do que os indivíduos podem fazer (ou seja, suas potencialidades), ao invés do que realmente estão fazendo. A operação de profiling realizada pela governamentalidade algorítmica evita que os indivíduos apareçam como agentes e não deixa espaço para que se tornem e se constituam como sujeitos.

A governamentalidade algorítmica não permite que 0 processo de subjetivação ocorra porque não encara os 'sujeitos' como agentes morais (evitando questioná-los sobre suas preferências e intenções, sobre as razões e motivações de suas ações), mas concilia seu futuro informativo e ambiente físico de acordo com as previsões contidas no corpo estatístico. A governamentalidade algorítmica precisa somente de um 'sujeito' único, supra-individual, 'corpo estatístico' constantemente reconfigurado feito de traços digitais infra-pessoais de facetas e interações impessoais, díspares, heterogêneas e divididas da vida diária. Este corpo estatístico infra- e supraindividual traz uma espécie de 'memória do futuro' visto que a estratégia da governamentalidade algorítmica consiste em garantir ou impedir sua atualização (ROUVROY, 2013, 157).

Nesse momento Rouvroy chega mesmo a enfatizar que a governamentalidade algorítmica não tem por objetivo a produção de sujeitos dóceis. Antes disso, e diferente de

\footnotetext{
${ }^{2}$ Mas aqui falamos de um estado de impotência e de inoperosidade ao qual os sujeitos são lançados não porque assim o desejaram, mas ao qual são encaminhados mesmo que não tenham a percepção de que a ele são direcionados. Nesse sentido a governamentalidade algorítmica age de tal forma que os indivíduos não percebam que são conduzidos a uma situação onde aceitam passivamente e sem questionamentos 0 fato de nada poderem fazer e serem impotentes para o fazer se o quisessem. Mas, no fundo, nem mesmo o querem visto que cedem qualquer tipo de liberdade, direito ou crítica em proveito de obter segurança, tranquilidade, serviços eficientes, etc. Isso está bem longe do que Agamben diz em A Potência do Pensamento quando se refere à passagem de Aristóteles na Metafísica (1046a 29-31) onde aborda precisamente a questão do copertencimento da potência e da impotência: toda potência é impotência do mesmo e a respeito do mesmo. Impotência não significa aqui ausência de toda potência, mas potência-de-não. "Na potência, a sensação é constitutivamente anestesia; o pensamento, não pensamento; a obra, inoperosidade. (...) Podemos dizer, então, que o homem é o vivente que existe de modo eminente na dimensão da potência, do poder e do poder não. (...) Os outros viventes podem somente sua potência específica, podem somente este ou aquele comportamento inscrito em sua vocação biológica; o homem é o animal que pode a própria impotência. A grandeza de sua potência é medida pelo abismo de sua impotência" (AGAMBEN, 2007, 361-362).
} 
diversos estudos de vigilância, é possível mesmo afirmar que ela "diminui os riscos de conformidade antecipativa dos comportamentos ou os efeitos inibidores associados à vigilância ubíqua" (ROUVROY, 2013, 157). A ocorrência disso se deve ao fato de que a governamentalidade algorítmica evita a todo momento qualquer confrontação e relação com os sujeitos. O que é diferente da visível e escópica vigilância que gera e impõe normas que são inteligíveis e ficam disponíveis para que qualquer um compare, sintonize, corrija e repense seus comportamentos. Nisso temos uma diferença bem significativa em relação à governamentalidade tal como pensada por Foucault porque não se busca uma construção de subjetividade, mas uma dessubjetivação ou mais radicalmente uma eliminação da subjetividade. Com a governamentalidade algorítmica os indivíduos, seus corpos, seus desejos, suas vontades, ele próprio em sua amplitude física, psicológica e espiritual é ignorado. Ele somente é objeto de interesse enquanto um "corpo estatístico", um "conjunto de dados" em constante crescimento e do qual é possível fazer correlações com outros "conjuntos de dados".

Em um contexto tão governamental as singularidades subjetivas dos indivíduos, suas motivações ou intenções psicológicas pessoais não são importantes. O que importa é a possibilidade de vincular qualquer informação ou dado trivial deixado para trás ou divulgado voluntariamente pelos indivíduos com outros dados coletados em contextos heterogêneos e estabelecer correlações estatisticamente significativas. O processo ignora a consciência individual e a racionalidade (não somente porque as operações de datamining são invisíveis, mas também porque seus resultados são incompreensíveis para os instrumentos da racionalidade moderna), e produz seus 'efeitos de governo' por 'adaptação' antecipativa do ambiente informacional e físico das pessoas de acordo com o que essas pessoas são susceptíveis de fazer ou desejar; e não adaptando as pessoas às normas que são dominantes em um determinado ambiente (ROUVROY, 2013, 157).

\section{CONSIDERAÇÕES FINAIS}

Com o inovador e atual deslocamento da governamentalidade proposto por Rouvroy temos uma nova configuração das formas de governo. O governo algorítmico não reconhece nada mais do que dados infra-individuais e perfis supra-individuais, sempre buscando evitar confrontos com sujeitos tanto no âmbito físico quanto no campo linguístico e das narrativas (basta pensarmos que testemunhos, declarações e outros modos de representação biográficas por meio dos quais o indivíduo fala de si estão se tornando inúteis para o Big Data). Portanto, este modo de governo pode ser pensado como o ponto alto de um processo de dissipação das condições institucionais, espaciais, temporais e linguísticas da subjetivação em proveito da objetividade e antecipação operacional de potenciais comportamentos.

Um governo algorítmico que molda o futuro, afetando indivíduos e grupos sobre o modo de lançar alertas e respostas reflexas, mas que nunca os confronta nem se expõe para ser desafiado pela liberdade humana, erradica as condições de crítica, priva os seres humanos de sua potência 
fundamental, que é sua capacidade de emergir como sujeito individual e coletivo em um 'comum' que é intersticial entre o mundo e a realidade (ROUVROY, 2013, 161).

Diante deste cenário o que fazer quando a própria forma de governo tem se estabelecido através de mecanismos que visam a imutabilidade, a proteção de todos os riscos e imprevistos que são inerentes ao próprio mundo e à própria existência de todos os seres? Alguns defendem a abertura e transparência dos métodos de funcionamento dos algoritmos. Mas essa saída seria infrutífera por algumas razões. A primeira seria a própria incompreensão humana da velocidade e quantidade de cálculos e correlações que realizam os algoritmos. A segunda diz respeito ao fato de que 0 funcionamento da governamentalidade algorítmica não ocorre apenas porque é opaca, mas também porque, segundo seus defensores, o próprio mistério de seus mecanismos e instrumentos impossibilita que quem tem seu perfil traçado impeça que isso ocorra (tornar transparente o funcionamento dos algoritmos que traçam o perfil de terroristas, por exemplo, pode tornar ineficaz a detecção de futuras ações criminosas e o impedimento de atentados). Talvez, uma possível forma de romper a barreira ou pelo menos resistir à esta nova forma de governar seria por um lado refletir sobre a configuração dos algoritmos e politizar sua utilização (como propõe Hugues Bersini) ${ }^{3}$, por outro lado tomar consciência das potenciais derivações da governamentalidade algorítmica (como proposto por Dominique Cardon). ${ }^{4}$

Além dessas formas de resistência à um governo algoritmo que se declara neutro e objetivo, mesmo que não tenha nada disso, ainda é possível citar outras práticas de resistência como o ativismo realizado pelo Movimento Hacker. Antoinette Rouvroy rechaça a defesa da abertura e transparência dos métodos de funcionamento dos algoritmos por considerar ser um assunto de difícil compreensão aos humanos devido à velocidade e

\footnotetext{
${ }^{3}$ Hugues Bersini é professor assistente na Université Libre de Bruxelles (ULB) e diretor do IRIDIA (laboratório de inteligência artificial da ULB) e membro da Académie Royale des Sciences, des Lettres et des Beaux-Arts de Belgique. Leciona ciência da computação, tecnologia da Web, business intelligence, programação e Inteligência Artificial. Realiza pesquisas que abrangem, entre outros, os domínios de ciências cognitivas e da tecnologia orientada a objetos. É autor de diversos livros e entre os mais recentes estão: Quand l'informtique reinvente la sociologie, Bruxelles: Académie Royale de Belgique, 2015 e Big Brother is driving you: brèves réflexions d'um informaticien obtus sur la sociétés à venis, Bruxelles: Académie Royale de Belgique, 2017.

${ }^{4}$ Dominique Cardon é sociólogo no Laboratoire des Usages (SENSE) da Orange Labs e pesquisador associado no Centre d'Études des Mouvements Sociaux (CEMS) da Ecole des Hautes Études em Sciences Sociales (EHESS). Seus estudos tratam das relações entre os usos de novas tecnologias e práticas culturais e midiáticas, interessando-se principalmente pela análise das transformações do espaço público sob efeito das novas tecnologias de comunicação. Suas pesquisas recentes abordam o algoritmo do Google, as relações sociais da internet, as formas de identidade on-line, a análise das formes de cooperação e de governo nos grandes coletivos on-line. É autor de, entre outros livros, $A ́$ quoi rêvent les algorithmes: nos viés à l'heure des Big Data, Paris: Seuil, 2015.
} 
quantidade de cálculos feitos pelos algoritmos. Mas tal atitude reforça a ideia de mistério de seu funcionamento.

A pesquisadora Cathy O'Neil, Matemática e Engenheira de dados, publicou recentemente o livro "Weapons of Math Destruction" (2016) onde denuncia de modo esclarecedor e contundente que os algoritmos são preconceituosos e reforçam estereótipos que consolidam as diferenças sociais, econômicas, de gênero, sexuais, entre outras. Os algoritmos são assim porque eles replicam o comportamento humano que ainda é tendencioso e recheado de preconceitos. Desse modo, as decisões algorítmicas se baseiam em um conjunto de dados enviesados que retroalimentam outros dados e decisões tendenciosas. A questão a ser colocada é se podemos confiar em dados que se baseiam em práticas e informações distorcidas e esperar que as diretrizes apresentadas pelos algoritmos não sejam por eles afetadas.

Diante dessa situação Cathy O'Neil afirma que é imperioso fiscalizar e averiguar se os dados e os algoritmos são justos e se nos dizem a verdade para, se necessário, efetuar a reparação e aperfeiçoamento necessários. É preciso realizar uma auditoria dos algoritmos: esta começa por uma checagem da integridade dos dados (estes estão corrompidos por vieses que dividem previamente pessoas e grupos como no caso de reincidência de crimes?); passa pelo exame cuidadoso da definição de sucesso (qual é o critério de sucesso que está presente no algoritmo analisado? Sucesso é ser alçado ao posto de diretor da empresa em 5 anos, trabalhar para o crescimento exponencial da empresa mesmo sabendo que seus diretores cultivam critérios antiéticos e sem responsabilidade social?); passa por uma análise do rigor dos acertos dos algoritmos (não existe o algoritmo ideal e perfeito, todos eles erram nos seus prognósticos - mesmo que a taxa de acerto tenha a tendência a crescer outros fatores devem ser considerados como o quanto os dados que os alimentam são tendenciosos); por fim, é preciso considerar como o viés algorítmico tem efeitos de longo prazo (os engenheiros de dados e programadores consideram o quanto seus algoritmos influenciam nas escolhas, decisões e formação das subjetividades? Como isso pode levar a criação de uma sociedade e um mundo que visa apagar as diferenças, é intolerante para com os outros, é passivo em relação às decisões políticas, etc).

\section{REFERÊNCIAS}

AGAMBEN, Giorgio. La potencia del pensamiento: ensayos y conferencias. Buenos Aires: Adriana Hidalgo Editora, 2007.

BERQUÓ, Elza Salvatori; SOUZA, José Maria Pacheco; GOTLIEB, Sabina Léa Davidson. Bioestatística. 1 $1^{\underline{a}}$ edição, $7^{a}$ reimpressão. São Paulo: EPU, 2001. 
FOUCAULT, Michel. O sujeito e o poder. In: DREYFUS, Hubert; RABINOW, Paul. Michel Foucault, uma trajetória filosófica: para além do estruturalismo e da hermenêutica. Rio de Janeiro: Forense Universitária, 1995, p. 231-249.

FOUCAULT, Michel. Technologies of the Self. In: MARTIN, Luther; GUTMAN, Huck; HUTTON, Patrick (orgs.). Technologies of the Self: a seminar with Michel Foucault. Massachusetts: The University of Massachusetts Press, 1988, p. 16-49.

O'NEIL, Cathy. Weapons of math destruction: how big data increases inequality and threatens democracy. New York: Crown Publishers, 2016.

ROUVROY, Antoinette. Governamentalidade algorítmica e perspectivas de emancipação: o díspar como condição de individuação pela relação?. Revista Eco Pós. Dossiê Tecnopolíticas e Vigilância. Vol. 18, no 02. Rio de Janeiro: UFRJ, 2015, p. 36-56. ROUVROY, Antoinette. Le droit à la protection de I avie privée comme droit à un avenir non pré-occupé, et comme condition de survenance du commun. (Draft / Version provisoite) Entretiens a propôs du droit a la protection de I avie privée (a paraitre). Ed. Claire Lobet-Maris, Nathalie Grandjean, Perrine Vanmeerbeek. Paris: FYP Editions, 2014. Disponível em: https://works.bepress.com/antoinette rouvroy/53/. Acessado em 23/06/2017. ROUVROY, Antoinette. Le gouvernement algorithmique ou l'“art" de ne pas changer le monde: les (n)ombres ou la vie. Draft / Version provisoite, 23/11/2016. Disponível em: https://www.academia.edu/30054245/Le gouvernement algorithmique ou I art de ne pas changer le monde. Les $n$ ombres ou la vie?auto=download. Acessado em 27/06/2017. ROUVROY, Antoinette. Technology, virtuality and utopia: governmentality in na age of autonomic computing. In: HILDEBRANDT, Mireille and ROUVROY, Antoinette (eds.). Law, Human Agency and Autonomic Computing: the Philosophy of Law meets the Philosophy of Technology. Abingdon, Oxford, New York: Routledge, 2011, p. 119-140.

ROUVROY, Antoinette. The end(s) of critique: data behaviourism versus due process. In: HILDEBRANDT, Mireille and DE VRIES, Katja (eds.). Privacy, Due Process and the Computational Turn: the Philosophy of Law meets the Philosophy of Technology. Abingdon, Oxford, New York: Routledge, 2013, p. 143-168.

VEIGA-NETO, Alfredo . Coisas de Governo... In.: RAGO, Margareth; ORLANDI, Luiz B. L. e VEIGA-NETO, Alfredo (org.). Imagens de Foucault e Deleuze: ressonâncias nietzscheanas. Rio de Janeiro: DP\&A, 2002, p. 13-34. 